\title{
Treatment of recurrent premenstrual orogenital aphthae with implants of low doses of testosterone
}

\author{
R Misra, D C Anderson
}

Department of Medicine (Endocrinology), University of Manchester, Hope Hospital, Salford M6 8HD

R Misra, MS, research fellow D C Anderson, FRCP, professor of endocrinology

Correspondence to:

Professor Anderson.

Br.11ed 7 1989:299:834
Recurring aphthous ulcers are painful and sometimes incapacitating. They affect the oral mucosa and, rarely, the genitals.' The cause is unknown. They may occur or increase in severity in the premenstrual phase of the cycle. Treatment is generally unsatisfactory.? We treated a patient whose intractable, cyclical orogenital ulcers responded to implants of low doses of testosterone.

\section{Case report}

A 29 year old nurse was referred to us with a history of recurrent orogenital ulcers since her late teens. The condition had worsened during the previous six years, when it became evident that it was related to her menstrual cycle. Each month she developed small painful red areas in her mouth and vulva around midcycle. These broke down to ulcers within a week. Usually four to six ulcers of about $1 \mathrm{~cm}$ diameter appeared at one or both sites. The ulcers healed a week after the menses, the symptoms thus lasting three weeks. She sometimes used aqueous tetracycline suspension with some benefit.

There were no other features to suggest a diagnosis of Behçet's disease. The results of haematological and hormonal investigations were normal. She had been taking the combined contraceptive pill since the age of 17.

She kept a daily record of her symptoms for three months while taking the contraceptive pill and for three months without the pill. This confirmed the cyclical pattern of the ulcers and showed that the contraceptive pill had no effect on her symptoms. Treatment with dydrogesterone for four months had no effect, although the ulcers no longer appeared in the premenstrual phase but appeared in the postmenstrual

phase. Finally, in February 1985, 100 mg testosterone was implanted subcutaneously. The ulcers gradually decreased in size and number over the next two months, and this was followed by a complete remission for one year. The ulcers then reappeared and gradually worsened. The patient requested another implant, which was given in February 1987. She received three more implants at intervals of about nine months. After each the benefit seemed to last for eight or nine months. The soreness in the vulva then recurred but did not progress to frank ulceration. She has had no mouth ulcers for two years.

The only side effect was the growth of a few hairs over the chin and breasts. Serum testosterone concentrations four, five, and eight months after implantation were $2 \cdot 9,3 \cdot 8$, and $1 \cdot 3 \mathrm{nmol} / 1$ respectively (normal $0 \cdot 5$ $2 \cdot 0 \mathrm{nmol} / \mathrm{l})$.

\section{Comment}

Recurring aphthae are rare in childhood, when boys and girls are affected equally before puberty. The incidence increases gradually, reaching a peak in the third decade, and women are affected more than men.' Because there is an endocrine factor contributing to the cause, Sircus in a single blind trial treated one patient each with oestrogen, androgen, and ethisterone (progestogen), but there was no response. ${ }^{3}$ Ferguson $e t$ al, however, showed that depot progestogens control such ulcers. ${ }^{+}$

Our patient's ulcers did not heal with treatment with oral progestogen. We tried testosterone implants because of our success in alleviating other more common premenstrual symptoms. ${ }^{5}$ The response was dramatic and is sustained while testosterone concentrations remain above normal.

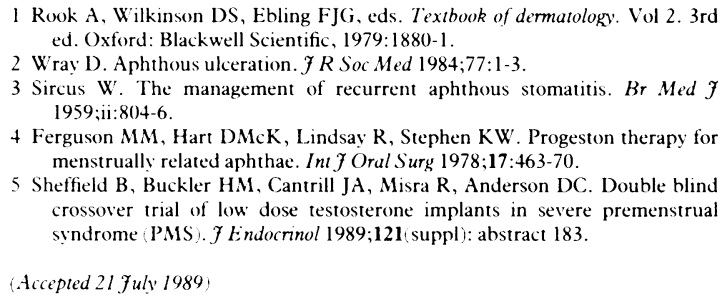

\section{Dietary salt affects biochemical markers of resorption and formation of bone in elderly women}

\section{B E McParland, A Goulding, A J Campbell}

Otago University Medical School, Dunedin, New Zealand

B E McParland, BSC, research student, department of human nutrition

A Goulding, PHD, senior research fellow, department of medicine

A J Campbell, FRACP,

professor of geriatric medicine

Correspondence to:

Professor Campbell.

Br.Med f 1989:299:834-5
High dietary intakes of sodium chloride increase calciuria and are considered a risk factor for osteoporosis. ' We investigated the short term effects of salt intakes of 70 and $170 \mathrm{mmol} / \mathrm{day}$ on variables of resorption of bone (urinary hydroxyproline excretion) and formation of bone (serum osteocalcin concentration) in elderly women.

\section{Subjects, methods, and results}

Ten healthy volunteers (mean (SD) age 66.8 $(1 \cdot 3)$ years) consumed diets low in salt and with salt supplements (100 mmol daily in divided doses with meals) for 10 days each. During each regimen they did not add salt during cooking or at the table and avoided salty foods. Calcium intake was held constant (about $850 \mathrm{mg} /$ day). Subjects took their normal diet for 10 days between the regimens. Twenty four hour urine collections were obtained on the last three days of each metabolic period to assess sodium, calcium, and creatinine excretions. On the 10th day of each period hydroxyproline excretion was measured, with subjects eating a gelatin free diet. On day 11 blood samples were obtained after an overnight fast for analysis of 1,25-dihydroxyvitamin D and osteocalcin concentrations; and fasting urine specimens were collected for measurements of cyclic AMP and creatinine excretions. Strontium absorption tests assessed intestinal absorption of calcium. ${ }^{2}$

The subjects were studied $18 \cdot 0(6 \cdot 2)$ years after the menopause and had a mean body mass index of $25.5(2.6) \mathrm{kg} / \mathrm{m}^{2}$. All had normal blood pressure and normal serum calcium and phosphate concentrations with no history of fractures, renal stones, or bone or endocrine disease; serum creatinine concentration was $<0.11 \mathrm{mmol} / \mathrm{l}$, alkaline phosphatase activity $<90 \mathrm{IU} / \mathrm{l}$, and serum 25-hydroxyvitamin D concentration $>21 \mathrm{nmol} / \mathrm{l}$. No subject took treatment likely to alter salt, calcium, or water handling. One subject had an episode of vomiting and was withdrawn from the study. Each subject gave informed written consent. 

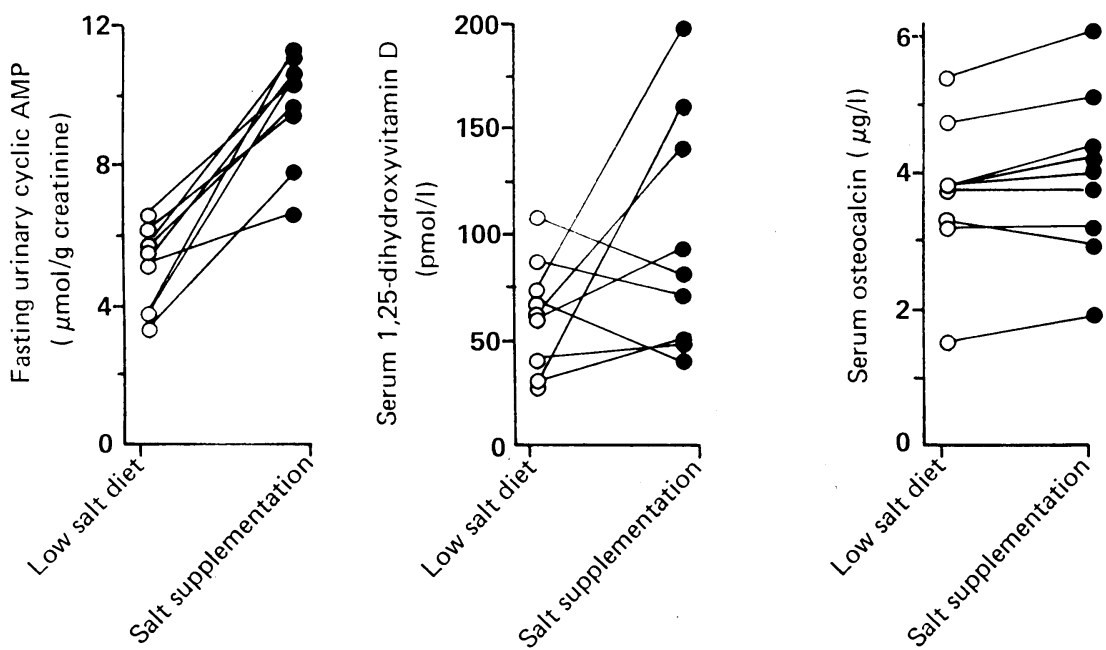

Urinary cyclic AMP excretion and serum 1,25-dihydroxyvitamin D and osteocalcin concentrations during low salt regimen and salt supplementation in nine healthy volunteers

Osteocalcin was measured by radioimmunoassay (Incstar Corporation, Minnesota) in a single assay of serum stored at $-80^{\circ} \mathrm{C}$ (coefficient of variation $=4 \cdot 2 \%$, $\mathrm{n}=10$ ). All other measurements were by standard techniques.' Significance (low salt regimen $v$ salt supplementation) was assessed with a two tailed paired $t$ test.

During salt supplementation 24 hour urinary sodium excretion rose from 70 (14) to $167(25) \mathrm{mmol}$ $(\mathrm{p}<0.001)$, calcium from $2.08(0.73)$ to 2.65 $(0 \cdot 88) \mathrm{mmol}(\mathrm{p}<0.001)$, and hydroxyproline from 158 (42) to $217(69) \mu \mathrm{mol}(\mathrm{p}<0.05)$ but creatinine did not change (rising from $9.3(1.5)$ to $9.9(1.5) \mathrm{mmol}$ ). Absorption of strontium did not increase (the proportion of the administered dose in extracellular fluid rose from $9 \cdot 0(3 \cdot 1)$ to $9 \cdot 3(3 \cdot 1) \%)$. The figure shows urinary cyclic AMP excretion and serum 1,25-dihydroxyvitamin $\mathrm{D}$ and osteocalcin concentrations; mean values rose from $5.0(1 \cdot 1)$ to $9 \cdot 7(1 \cdot 6) \mu \mathrm{mol} / \mathrm{g}$ creatinine $(\mathrm{p}<0.001), 61.9(26.4)$ to $98.6(55.9) \mathrm{pmol} / \mathrm{l}$, and $3.7(1 \cdot 1)$ to $4.0(1 \cdot 2) \mu \mathrm{g} / 1(\mathrm{p}<0.05)$, respectively.

When the subjects took their normal diet 24 hour urinary sodium excretion (109 (28) $\mathrm{mmol})$, calcium $(2 \cdot 24(1 \cdot 0) \mathrm{mmol})$, hydroxyproline $(179(88) \mu \mathrm{mol})$, and creatinine $(9.7(1.4) \mathrm{mmol})$ were intermediate between the values obtained during the low salt regimen and salt supplementation.

\section{Comment}

Moderate variations in dietary salt intake influenced variables of resorption and formation of bone in elderly women. The rise in hydroxyproline excretion indicated increased resorption of bone due to increased parathyroid activity. ${ }^{13}$ The increased urinary cyclic AMP excretion indicated raised parathyroid hormone concentrations. The small rise in osteocalcin concentration indicated increased formation of bone. ${ }^{+}$ Changes in osteocalcin concentration mediated by salt have not been reported previously.

Breslau et al reported a significant increase in 1,25-dihydroxyvitamin D concentrations in young subjects given salt loads ${ }^{3}$ but no increase in older women with osteoporosis. ' In our study 1,25dihydroxyvitamin D concentrations increased, though not significantly. Our index of alimentary absorption of calcium (absorption of strontium) did not rise. Increased 1,25-dihydroxyvitamin D concentration probably triggered the small rises in osteocalcin concentration we observed. ${ }^{+}$Alternatively, some unidentified factor(s) coupling resorption and formation of bone may have been responsible.

Women who lose bone shortly after the menopause have a net negative calcium balance of about $1.0 \mathrm{mmol} / \mathrm{day}$. In our study modest supplementation with salt raised urinary calcium excretion by $0.57 \mathrm{mmol} /$ day. Because calcium requirements will be lower with low salt intakes, decreasing salt intake should benefit the skeletons of women susceptible to type II (senile) osteoporosis.

This work was supported by bequest funds to Otago Medical School and by the Medical Research Council of New Zealand. The Otago Hospital Board ethical committee approved the protocol

1 Goulding A. Everitt HE, Coones JM, Spears GFS. Sodium and osteoporosis. In: Truswell AS, Walqvist ML, eds. Recent advances in clinical nutrition. In: Truswell AS, Walquist ML, eds. Recent

2 Milsom S, Ibbertson HK, Hannon S, et al. Simple test of intestinal calcium absorption measured by stable strontium. Br Med f 1987;295:231-4

3 Breslau NA, McGiuire JL, Zerwekh JE, Pak CYC. The role of dietary sodium on renal excretion and intestinal absorption of calcium and on vitamin D metabolism. I Clin Endocrinol Metab 1982;55:369-73.

Lian JB, Gundberg CM. Osteocalcin. Biochemical considerations and clinical applications. Clin Orthop 1988;226:267-91.

Breslau NA, Sakhaee K, Pak CYC. Impaired adaptation to salt-induced urinary calcium losses in postmenopausal osteoporosis. Trans Assoc Am Physicians 1985:98:107-15.

Accepted 26 fune' 1989)

\section{Overtreatment of children with Wilms' tumour outside paediatric oncology centres}

\section{Hospital for Sick Children, Great Ormond Street, London WC1H 3JH \\ J Pritchard, FRCP, consultant in oncology}

Childhood Cancer

Research Group, Radcliffe Infirmary, Oxford

OX2 6HE

C A Stiller, MSC, research officer

E L Lennox, MB, research officer

Correspondence to: Dr Pritchard.

\section{J Pritchard, C A Stiller, E L Lennox}

The main clinical objective of research into cancer is to identify the minimum treatment necessary for cure to reduce the impact of toxicity. By 1979, in a series of randomised trials, the United States national Wilms' tumour study had established that $(a)$ patients with stage I disease in whom the histological appearance indicates a favourable prognosis do not need abdominal radiotherapy and need at most six months' chemotherapy with two drugs, vincristine and actinomycin $\mathrm{D} ;(b)$ those with stage II tumours with a favourable prognosis need a maximum of $20 \mathrm{~Gy}$ hemiabdominal radiotherapy and 15 months' chemotherapy with the two drugs; and $(c)$ those with operable stage III disease with a favourable prognosis need 10-20 cGy abdominal or hemiabdominal radiation and 15 months' treatment with vincristine, actinomycin $\mathrm{D}$, and adriamycin. In the first two studies over $90 \%$ of children in these three categories survived free of disease more than five years after diagnosis and were presumed to be cured.'

The first study of Wilms' tumour by the United Kingdom Children's Cancer Study Group started in 1979 and incorporated several refinements of treatment, some derived from results of the Medical Research Council's second trial ${ }^{2}$ - for example, besides surgery only vincristine was used in patients with stage I disease in whom the histological appearance indicated a favourable prognosis. Only children in whom the histological appearance indicated an unfavourable prognosis and those with stage IV tumours (a fifth of the total) received abdominal radiation of $>20 \mathrm{~Gy}$ and intensive chemotherapy.

In another study children with Wilms' tumour treated outside paediatric oncology centres during 1977-84 had a similar overall survival to that of children managed elsewhere, ${ }^{3}$ but some seemed to have received more treatment than was appropriate. The present study assessed treatment of British children 